\title{
THE RELEVANCE OF THE DEVELOPMENT OF PERCEPTUAL ABILITIES IN CHILDREN OF PRIMARY SCHOOL AGE
}

\author{
Alina Yerofeyeva ${ }^{1}$, Tatyana Kokhanover ${ }^{2}$ \\ ${ }^{1}$ E.A.Buketov Karagandy University, Kazakhstan \\ ${ }^{2}$ E.A.Buketov Karagandy University, Kazakhstan \\ ORCID ID:0000-0002-3353-8742
}

\begin{abstract}
Article is devoted to the study of the peculiarities and importance of the development of perceptual abilities of children studying in primary school. First of all, the concept of perception, classification and properties are considered for further understanding of the topic. The article includes a comparison of perception by age groups and shows by the example of an experiment how much perception skills affect the lives of primary school children. The peculiarities of the psyche of children aged 7-10 years, such as concentration time, attentiveness, perception of time, were taken into account. Basically, the article touches on certain types of perceptual abilities, such as visual and auditory perceptions. These types of perception skills are of the greatest importance in the development of children.
\end{abstract}

\section{INTRODUCTION}

From an early age, children are drawn to mastering, first of all, their native language. The fact that they perceive their parents' speech, imitate words, shows how important language knowledge is in our lives. The child acquires its development when interacting with other native speakers of the same language. A person from a very young age acquires language skills through the prism of perception: listening to the speech of parents and other people, observing the world around them, repeating words already heard, even if he is not yet able to understand their meaning. According to psychological research, the active phase of learning knowledge is the age from 1.5 to 9 years. At this age, basic speech skills are formed, the brain best perceives and remembers the sounds of not only the native, but also a foreign language. In this regard, perceptual abilities play an important role in the development of the child, as they are the basis. Perceptual abilities are laid down in very early childhood and are present in adults, but they do not develop so actively. The foundation for this should be laid in childhood, along with new experiences. It shapes how people hear and see, that is, it contributes to perception. In the psychological sphere, this refers to perceptual learning, which is the relationship between experience and perception.

The concept of human perception is described by psychologist A.G. Maklakov in his work "General Psychology" as: "a holistic reflection of objects, situations, phenomena arising from the direct impact of physical stimuli on the receptor surfaces of the sensory organs." [Maklakov, 2001]. From childhood, the basis of such a cognitive process as perception is the presence of various sensations and their course. B.G. Ananyev in his work "Individual human development and constancy of perception" considered sensation and perception as two different stages of a single process of sensory cognition. He implies that these two phenomena are not the same, but sensation is part of perception. In addition to them, this process involves a person's previous experience and awareness of what is perceived at this point in time. Based on these theses, it can be understood that processes in the psyche, such as memory and thinking, are included in the perceptual process. According to A.G. Maklakov, the perceptual system of man is called perception. The physiological basis of perception includes processes taking place in the sensory organs, in the central nervous system and its fibers. The physiological basis of perception includes a perceptual action indicating the basic units of the structure of the perception process. Such basic units transform sensory information into an image.

Perceptual action is divided into four levels, in other words, operations, and proceeds in a 
strictly defined order as shown in figure 1.

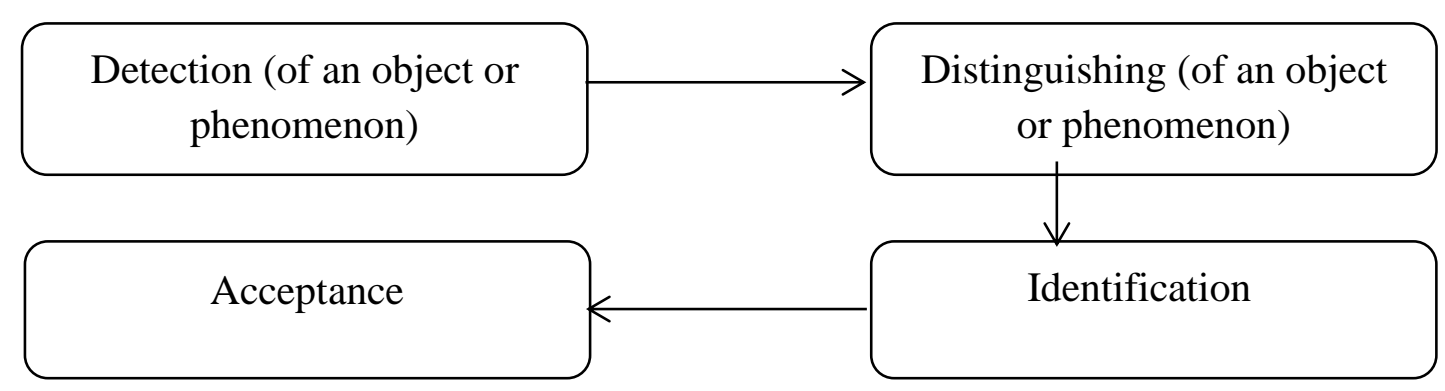

Figure 1. Scheme of perceptual skills

The detection of an object or phenomenon is the initial, basic phase in the formation of any sensory processes. The distinction is perceptual, since its result is the creation of a perceptual image, only after this stage identification steps are possible. Identification is a comparison of a directly perceived object with an image that has been preserved in human memory, or a comparison of several perceived objects at the same time. Acceptance, as the final level, means dividing into categories, assigning an object to a specific class of objects already remembered and, in the end, obtaining the corresponding sample from memory.

Based on these theses, it can be understood that such processes in the psyche as memory and thinking are included in the perceptual process. Maklakov determined that the perceptual system of a person is called perception [Maklakov, 2001]. The physiological basis of perception includes the processes taking place in the sensory organs, in the central nervous system and its fibers.

Perception is formed not only on the basis of sensory sensations, but also such perceptual abilities as visual and auditory, but they all form a set of concepts and an image of an object. To identify an object and create its image, there are a number of certain signs.

As a cognitive thought process, perception is as important as attention, thinking and memory [Gusev, 2009,]. A.N. Gusev identified several properties:

- The objectivity of perception is the reflection of objects and the surrounding reality in the form of separate sensations, and not in the form of sensations that are not interconnected with each other.

- The integrity of perception is not a reflection of the sensation of individual properties, but of the general and integral image of the object.

- Constancy of perception is the constancy of the properties of reflections of objects, when the conditions for their perception change.

- The structure of perception is a reflection of the image of an object or phenomenon not in the sum of sensations, but its generalized structure.

- Apperception is the perception of an object or phenomenon as a perceptual image, depending on the mental activity of the perceiver.

- Meaningfulness is the presence of semantic content in objects or phenomena perceived by a person.

- Activity (selectivity)- the perception of a certain object at the moment, while the rest of the objects are just the background.

In modern psychological literature, there are several approaches to the classification of perception (Figure 2). The basis of this classification of perception are differences in analyzers involved in perception and sensations.

The basic ways of perception of primary information are perception channels. The original exact channel of perception implies a receptor. A receptor is a sensitive cell that picks up a particular stimulus. For example, light waves picked up by the eye receptors, or sound vibrations that are perceived by the auditory receptors. In this regard, there are several channels of modalities or perception: visual, auditory and kinesthetic channels of perception. With the help of the modality, 
which is the leading channel for receiving information, there is also a processing of the information received from the outside world. For example, an auditory student may hear an error in the speech of another in a foreign language lesson. It will be easier for visuals to perceive the information written on the blackboard than repeating the material orally.

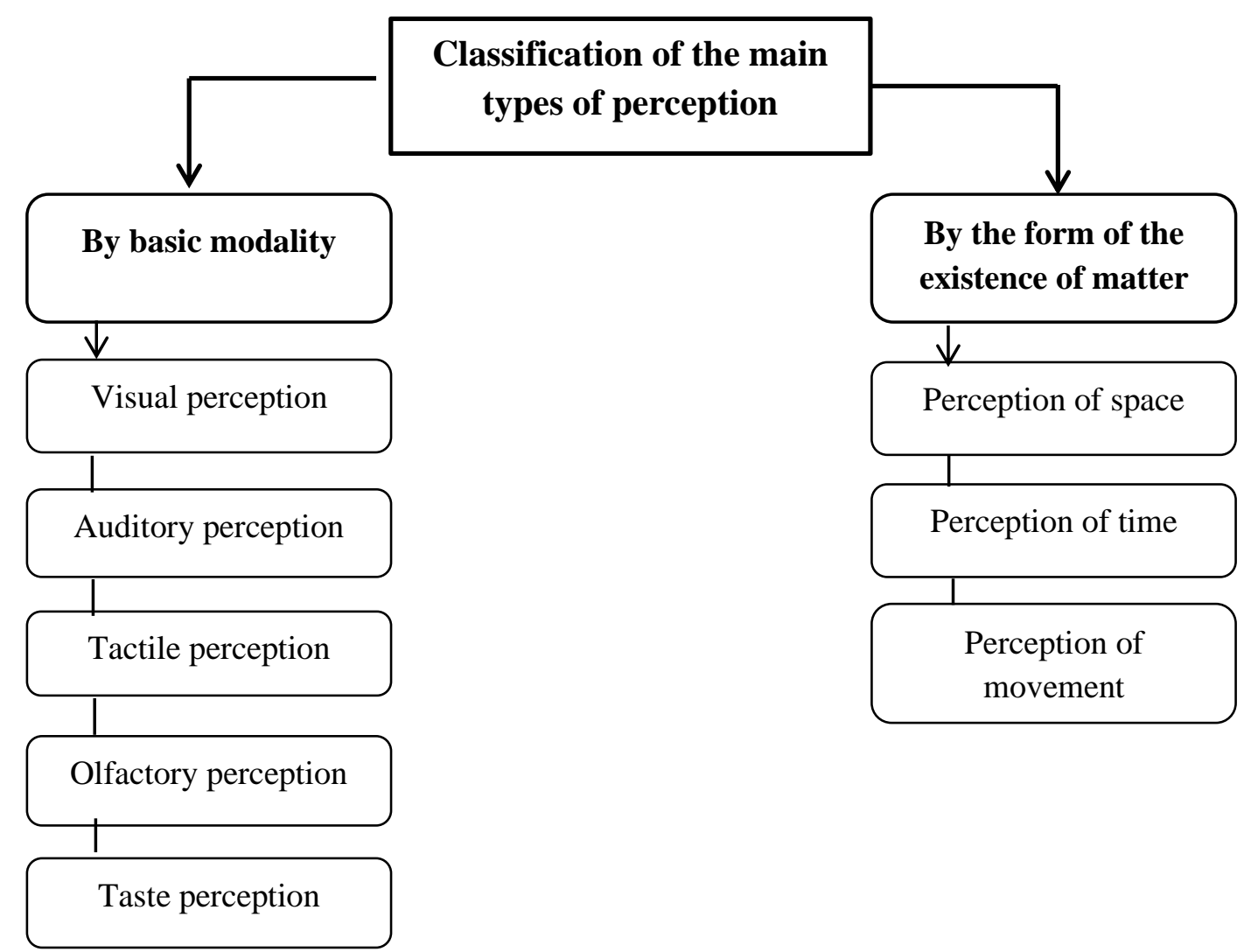

Figure 2 Classification of the main types of perception

During the process of studying at school, the child actively develops perception, which takes place in several stages during this period of life. The first of them is determined by the formation of an adequate image of an object during the process of manipulation of this object. The next stage introduces the child to the properties of the space of objects when using hands and eyes. Further stages of the development of the psyche are already high stages and are characterized by children's abilities, without external movements, for a short time to recognize certain properties of objects perceived by them, and, in addition, to distinguish objects from each other based on these properties. Participation of any actions no longer accompany the perception process itself.

The most active phase of the development of perceptual-sensory abilities is the age from 2 to 6 years. During this period of life, the child actively develops and learns about the world with the help of physical development and improving the work of receptors. Perception develops according to the basic modality and according to the modality of the form of matter. Both modalities are reflected in the child and prepare him for life. For example, psychologists can understand how prepared a seven-year-old child is for school by how well he has formed perceptual skills because they are fundamental. More complex stages related to sociality and reflection depend on sensory-perceptual abilities, that is, we can say that this is like a strong foundation. Socio-perceptual and perceptualreflexive abilities begin to develop when the child is identified as a whole person and he can already perceive himself in a variety of social roles. It should be borne in mind that if there is a violation or distortion of the process of development of one or more basic abilities such as impaired vision, hearing, motor-motor apparatus, then socio-perceptual and perceptual-reflexive abilities may not 
manifest in any way, or in the form of a defected one.

In the work of B.G. Ananyev "Individual development of a person and the constancy of perception" was considered the dependence of the visual channel of perception on the age of the participants in the experiment (Figure 3) [Ananyev, 1968]

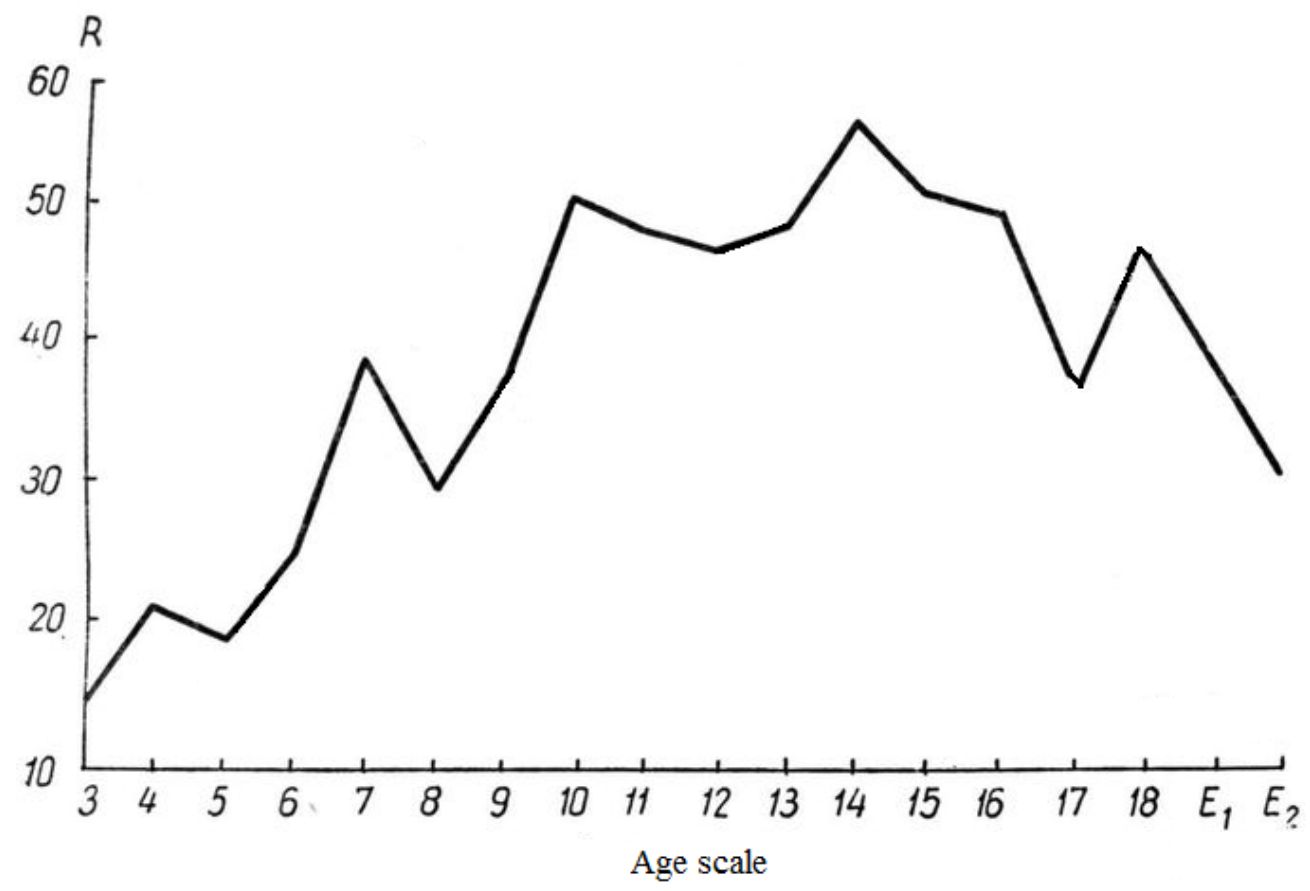

Figure 3 The form constant as a function of age (according to Klimpfinger).

S. Klimpfinger included people aged 3 to 70 years in her study. It should be noted that children are divided into more frequent age intervals, and adults are grouped into two groups: $\mathrm{E}_{1}$ - participants of the experiment aged from 19 to 30 years, in group $E_{2}$ - from 31 to 70 years. This is due precisely to the fact that in childhood and adolescence, perceptual abilities develop much more rapidly than in adulthood. In childhood, there is an adaptation to the world and the creation of images, in adolescence it becomes more complicated and important not just learning, but communication. After adolescence, these abilities already fade into the background in the sense of skill development, but nevertheless belong to the basic ones. Perception goes through all the stages of a human's life.

Alfred Binet made the wrong conclusion that perceptual abilities have strict age-related limits, regardless of the content of the perceived object or phenomenon. He drew up a scheme that establishes three age levels of perception, in a situation where children are shown images on cards:

Table 1. Levels of perception

\begin{tabular}{|l|l|}
\hline Age & Stages of visual perception \\
\hline $3-7$ y.o. & Listing of individual items shown in the pictures \\
\hline $7-12$ y.o. & $\begin{array}{l}\text { The stage of describing objects, their color, } \\
\text { shape, texture }\end{array}$ \\
\hline 12 years and older & $\begin{array}{l}\text { The stage of explanation and interpretation why } \\
\text { the subject is used, in which situations }\end{array}$ \\
\hline
\end{tabular}

S. Rubinstein and Hovsepyan refuted this assumption. According to them, if children are shown images with already familiar content, for example pictures with close relatives, children from 
the age of three may not be limited with a simple enumeration, if based on the Binet scheme, the child can give a more or less related story, even with the addition of fictional explanations and fantasies.

Based on this, we may understand that the qualitative feature of the content of children's perception is caused, first of all, by the limited experience of each child individually, the insufficiency in the systems of temporary connections that were formed in the past experience, the incorrectness of the differentiations developed before.

Consider the psychological characteristics of elementary school students. The student develops several modes of perception and certain properties of the mentality:

- Development of auditory and visual perception modality;

- perception of time;

- concentration;

- attention.

Visual and auditory modalities are best formed in lessons related to the development of languages (Kazakh, Russian, English). In addition, the school improves the perception of time, which is a perceptual ability in the form of the existence of matter. As an example, if you tell the children of the first or second grade that they have five minutes left to complete the task, they will not be able to really estimate the remaining time. The minimum age of awareness is the fourth grade, at preschool age children do not even have the concept of the concreteness of time. In this regard, it is important for the teacher to be reminded of the importance of concentration on the exercise every two or three minutes [Lublinskaya, 1997]. Time also matters in terms of focusing on one particular activity. Children under the age of seven have an attention span of 5 to 10 minutes, children aged 8-10 years concentrate only from 10 to 15 minutes, after this period of time it is necessary to change the type of activity.

Based on the knowledge of perception by age, let's turn to school age, and especially to the primary school. Students come to school with different levels of development of perception skills, but at this age it is still fixable. At school age, perception becomes, in addition, more complex, multifaceted and purposeful. The school, together with a variety of educational and extracurricular activities, opens up to students a complex picture of the world, natural and social situations, forms their perception and observation. During the transition to the middle classes, it will be more difficult for children with undeveloped abilities to move to more advanced levels of perceptual skills.

The visibility of learning for the development of perception at school age is very helpful. Practical classes, compiled systematically, and laboratory work, a variety of visual aids, various excursions all these types of classes are only a small part of what can provide significant content material for the development of perceptual abilities and observation skills of students. Improving the perception skills of students requires special attention and regulation on the part of adults, that is, teachers and educators. In particular, it is worth considering elementary school students who, due to the inferiority of life experience, often cannot calculate the main and essential in the phenomena under consideration, have difficulties in describing them, miss important details and are distracted by other random and insignificant ones.

The task of the teacher is to thoroughly prepare students for the perception of the studied objects (in our case, in the English lesson) and to communicate the necessary data about them, which can facilitate and direct the development of perceptual skills in children towards highlighting the most important features of phenomena or objects. Mikhail Skatkin, a Russian teacher, gave an example of an incorrect task: a first-grade teacher showed a card with an image of a squirrel and told about the structure of their life, but did not note the peculiarities of the appearance of the animals. After she put away the card with the picture, she offered to draw the missing details to a pre-prepared stencil with a squirrel. It turned out to be quite unexpected for the teacher that many first-graders could not do this job. There were a lot of questions about the color of the fur, the presence of a mustache or claws. The teacher should not just demonstrate the material, but also direct the children's attention to the subject of study. Especially care should be taken about the correctness of perception and observation. At the initial stages, children's abilities may not be so detailed. This is a natural phenomenon when a child encounters an object for the first time, but perception should never be distorted and arbitrarily 
interpreted.

The relevance of the development of perceptual abilities lies in the fact that with the help of them, the child begins to develop from a young age, when he learns the world around him, and at a later age moves to complex stages associated with human social life. These are skills that are laid down from early childhood and are reflected in a person until old age.

\section{REFERCNCES:}

Ananyev, B. G., Dvoryashina, M. D., Kudryavtseva, N. A. (1968) Individualnoe razvitie cheloveka I constantnost vospriyatiya [Individual human development and constancy of perception ], Vol. 6 [in Russian]

Maklakov A.G. (2001) Obshaya psikhologiya [ General psyschology] Moscow [in Russian]

Gusev A.N. (2009) Obshchaya psikhologiya. Oshchushcheniye i vospriyatiye Tom (chast') 2.: Uchebnik dlya studentov vysshikh uchebnykh zavedeniy [General psychology. Sensation and perception Volume (part) 2 .: Textbook for students of higher educational institutions], 2nd ed., Sr., M .: Academy[in Russian].

Lublinskaya, A. A. (1977) To Master about Psychology of Younger Schoolchildren [Text] / A. A. Lublinskaya. - Moscow, Education [in Russian] 